\title{
A case of ocular syphilis in HIV positive man
}

\author{
Vesta Kucinskiene', Arunas Petkevicius ${ }^{1}$, Daiva Paulaviciute-Baikstiene², Reda Zemaitiene², \\ Janina Vasilaviciene ${ }^{3}$
}

${ }^{1}$ Department of Skin and Venereal Diseases, ${ }^{2}$ Department of Ophthalmology, Medical Academy, Lithuanian University of Health Sciences (LUHS), Hospital of Lithuanian University of Health Sciences Kauno klinikos, Kaunas, Lithuania, ${ }^{3}$ Clinic of Skin and Venereal Diseases, Kaunas Clinical Hospital, Kaunas, Lithuania

Background: The numbers of reported syphilis in Lithuania decreased from 7.5 (in 2012) to 5.5 cases (in 2017) in 100000 population (Table 1). During the last five years in the Hospital of LUHS there were diagnosed 18 cases of late syphilis and 6 of them were cases of ocular syphilis. We present the case of ocular syphilis in HIV positive man in order to illustrate the problem's actuality.

Case report: A 38 old year man referred to the Department of Ophthalmology complaining of blurred vision in both eyes and headache over the past two months. The patient had no eye disorders also other concomitant diseases previously. Ophthalmological examination revealed the signs of acute iridocyclitis (Fig. 1,2) and vitreitis (Fig. 3) in both eyes. Laboratory analysis of complete blood count, biochemical, immunological tests was normal. Serologic tests for syphilis were positive: RPR titre 1:256, TPHA 4+. Cranial computer tomography images were without pathological variations. Cerebrospinal fluid (CSF) analysis revealed that TPHA was positive and VDRL-CSF titre 1:16. Also positive HIV ELISA and confirmatory western blot was identified. The treatment with short acting intravenous benzylpenicilline (18 million units/day) was administered. The patient was also consulted by infectionist for AIDS treatment. After the patient was informed of the diagnoses of STIs he told that he was already treated for syphilis 3 years ago with injectable antibiotics but he didn't come for serologic control after treatment and sexual partners were not treated as the patient didn't refer them. The patient denied usage of intravenous drugs.

Conclusions/Lessons Learned: though the numbers of syphilis decreased in Lithuania, the specialists should be often reminded about it's emergence in the forms of late stage (ocular, cardiovascular syphilis, etc). Our case reminds the importance of patient's follow-up after treatment and also contact notification, as risky sexual behaviour could lead to severe complications of the infection.

\section{References:}

1. Dutta Majumder P, et al. Ocular Syphilis: An Update. Ocul Immunol Inflamm. 2017, 11:1-9.

2. Davis JL. Ocular syphilis. Curr Opin Ophthalmol. 2014;25(6):513-8.

3. Woolston SL, et al. Ocular Syphilis: a Clinical Review. Curr Infect Dis Rep. 2016 Nov;18(11):36.
Table 1. Incidence of syphilis and HIV infection in 2013-2017 in Lithuania (data from the Centre of Communicable Diseases and AIDS)

\begin{tabular}{|l|l|l|l|l|l|l|}
\hline STI & $\begin{array}{l}\mathbf{2 0 1 3} \\
\text { new } \\
\text { cases }\end{array}$ & $\begin{array}{l}\mathbf{2 0 1 4} \\
\text { new } \\
\text { cases }\end{array}$ & $\begin{array}{l}\mathbf{2 0 1 5} \\
\text { new } \\
\text { cases }\end{array}$ & $\begin{array}{l}\mathbf{2 0 1 6} \\
\text { new } \\
\text { cases }\end{array}$ & $\begin{array}{l}\mathbf{2 0 1 7} \\
\text { new } \\
\text { cases }\end{array}$ & $\begin{array}{l}\mathbf{2 0 1 7} \\
\text { Incidence } \\
/ 100000\end{array}$ \\
\hline $\begin{array}{l}\text { Infectious } \\
\text { syphilis }\end{array}$ & 269 & 257 & 281 & 151 & 157 & 5.5 \\
\hline $\begin{array}{l}\text { HIV } \\
\text { infection }\end{array}$ & 168 & 136 & 154 & 214 & 263 & 9.3 \\
\hline
\end{tabular}

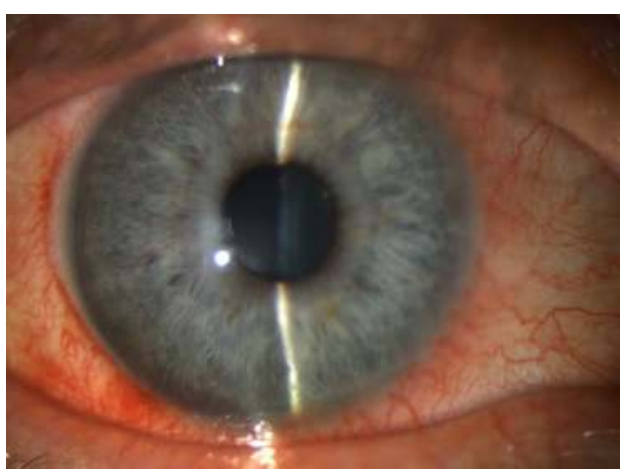

Figure 1. Iridocyclitis

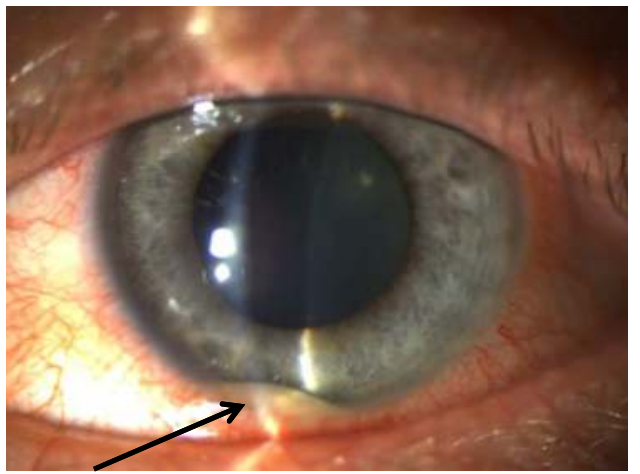

Figure 2. Hypopyon

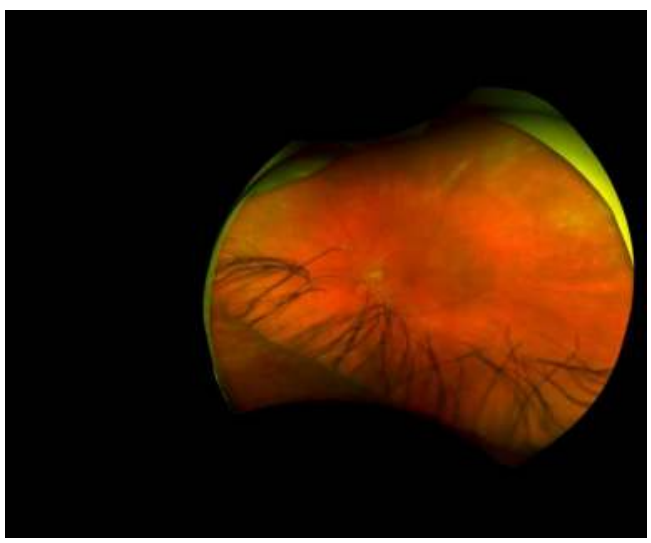

Figure 3. Vitreitis 